\title{
Amodiaquine-Associated Asthenia: A Case Based Review and Gaps in Literature
}

\author{
Obaro S. Michael ${ }^{1,}$ ", Joseph A. Badejo1, Adewale G. Bakre ${ }^{1}$, Adebola E. Orimadegun ${ }^{2}$, Olusegun G. Ademowo ${ }^{1}$, \\ Catherine O. Falade ${ }^{1}$ \\ ${ }^{1}$ Department of Pharmacology and Therapeutics, Faculty of Basic Medical Sciences, College of Medicine, University of Ibadan, Nigeria \\ ${ }^{2}$ Department of Pediatrics, Faculty of Clinical Sciences, College of Medicine, University of Ibadan, Nigeria
}

*Corresponding Author: Obaro S. Michael, MD, Department of Pharmacology and Therapeutics, Faculty of Basic Medical Sciences, College of Medicine, University of Ibadan, Nigeria. Tel: +2348056642410, Email: micobaro@gmail.com

\begin{abstract}
Introduction: Amodiaquine is a partner drug in the artemisinin-based combination therapy artesunate-amodiaquine. Reports of the adverse drug reaction known as amodiaquine-associated asthenia are scarce, and this adverse reaction needs to be investigated in detail. This article presents and reviews a case of amodiaquine-associated asthenia. A literature search for the characteristics of this adverse reaction highlighted gaps in the literature.

Methods: A case of probable amodiaquine asthenia was described and discussed under the sub-headings of epidemiology, clinical features, laboratory features, aetiopathogenesis, and management. A literature search limited to Medline Health Databases (Medline and PubMed Central, PMC) using the search terms <amodiaquine AND adverse reaction> and <amodiaquine AND asthenia> was conducted on 10 March 2015. Retrieved literature on the subject was closely scrutinized for relevant details of adverse drug reactions to amodiaquine when used in the management or prophylaxis of malaria. Cited literature within retrieved manuscripts was examined manually for other relevant literature. Papers retrieved from the search were used to describe the existing knowledge and gaps in it of the adverse drug reaction under sub-categories of incidence, clinical features, laboratory features, aetiopathogenesis, and management.

Results: Thirty-nine manuscripts were retrieved; 20 had content relevant to the objectives of this review. The frequency of amodiaquine-associated asthenia in different populations ranged from $12-36 \%$. There is a paucity of reports, and no detailed study of this adverse reaction has been published in popular English medical literature.

Conclusion: With the use of amodiaquine as a partner drug in antimalarial combination therapies being scaled up, well-structured studies are needed on adverse reactions to amodiaquine and to investigate amodiaquine-associated asthenia. In addition, approaches to elucidating this adverse reaction more effectively in children need to be developed.
\end{abstract}

Keywords: Amodiaquine, Asthenia, Weakness, Malaria, Nigeria

Article History: Received: 31 Mar. 2016; Accepted: 28 Apr. 2016; Online Published: 25 Jun. 2016

Cite this article as: Michael OS, Badejo JA, Bakre AG, Orimadegun AE, Ademowo OG, Falade CO. Amodiaquine-associated asthenia: a case based review and gaps in literature. Int J Travel Med Glob Health. 2016;4(2):41-6. doi: 10.20286/ijtmgh-04022

\section{Introduction}

Adverse drug reactions (ADRs) are a global problem in both developed and developing countries, and different approaches to monitoring and reporting them exist in different countries [1]. There are many challenges to identifying, managing, and reporting ADRs in children because of their inability to communicate effectively; Presentation becomes even more challenging for cases in rural communities where a large proportion of people with infectious diseases reside [2-4]. A high index of suspicion, knowledge of the varieties, and patterns of presentation are required for prompt and effective responses to ADRs [5].

Malaria constitutes a huge burden in endemic countries where antimalarial therapies are currently among the most frequently prescribed medications [6]. Malaria is the most common cause of hospital attendance in all age groups in all parts of Nigeria. It is also one of the four most common causes of childhood mortality in the country, the other three being acute respiratory infection (pneumonia), diarrhea, and measles [7]. It is estimated that $50 \%$ of the population has at least one episode of malaria each year, while children under 5 have on average 2-4 attacks per year [7]. Artemisininbased combination therapies (ACTs) are increasingly being deployed. An artesunate-amodiaquine combination is frequently used in the treatment of acute uncomplicated malaria in Nigeria.

Amodiaquine is an 8-aminoquinoline used for the therapy of chloroquine-resistant malaria [8]. The drug is an important partner drug in artemisinin-based therapies, perhaps second in use only to artemether-lumefantrine. The recommended dosage is $10 \mathrm{mg} / \mathrm{kg}$ of amodiaquine base once daily for 3 days, usually in combination with artesunate. Amodiaquine has been linked to severe cases of acute hepatitis and agranulocytosis which can be fatal. Because of these severe adverse reactions, the drug is not recommended for prophylaxis against malaria [9]. Other side effects of amodiaquine include nausea, diarrhea, skin rash, itching, and weakness. These side effects, although mentioned in reports of clinical trials, are often not evaluated in detail [10, 11].

Generalized body weakness has been reported to occur in up to $36 \%$ of those receiving amodiaquine-based artemisinin combination therapies, and the effect has been attributed largely to the amodiaquine component [12]. The incidence of weakness in children is difficult to estimate because, among other reasons, of their inability to complain, and it is believed that incidence in children may be under-estimated. Although this complaint is often encountered, there is a paucity of reports describing it in detail. In addition, there is no standardized format for reporting and describing such an adverse drug reaction.

This report, which is a general rather than systematic review, presents a case of highly probable amodiaquineassociated asthenia in a child presenting at a community health center; using the features of presentation, the authors 
searched for relevant literature on this adverse drug reaction. Although a single case report is limited, it is believed that that this case of highly probable amodiaquine-associated asthenia can be used to guide a literature review that will highlight what is known about the drug reaction and point out gaps in the literature. This approach is targeted at raising the index of suspicion so as to assist in recognizing, monitoring, managing, and reporting cases of amodiaquineassociated weakness that may present at health centers of malaria endemic countries where the use of amodiaquine containing artemisinin-based combination therapies has become popular in recent years.

\subsection{Case Review}

\subsubsection{Demography}

A 33-month-old female child who resides in a rural area was brought to the primary health center by the mother on account of an acute febrile illness.

\subsubsection{Presenting Clinical Features}

The child presented with a three-day history of fever, anorexia, and non-projectile vomiting. There was no history of convulsion, cough, or diarrhea. Physical examination revealed mild dehydration, pyrexia (axillary temperature $38.0{ }^{\circ} \mathrm{C}$ ), pallor, no jaundice, and no palpable enlarged abdominal organs (liver or spleen). Other physical findings were unremarkable. The patient's mother denied giving the patient any medication other than oral paracetamol before presentation.

\subsubsection{Laboratory Findings}

Investigations included a full blood count (FBC), blood culture, blood smears for malaria parasites, malaria rapid diagnosis test, and urine microscopy. A blood smear for malarial parasites was positive (2300 parasites/uL); the malaria rapid diagnosis test was also positive. Blood cultures and urine microscopy were negative for any pathogen. The FBC did not suggest a bacterial infection. An acute falciparum malaria infection was diagnosed. Hematocrit value at presentation was $23 \%$.

\subsubsection{Management}

The child commenced a three-day standard dose of artesunate-amodiaquine $(10 \mathrm{mg} / \mathrm{kg}$ of amodiaquine component daily for three days). The nurse on duty administered the first dose of the medication, and the child was observed for one hour before going home. The mother was instructed on providing adequate fluids, food intake, and when and how to administer other doses of the medication. She was instructed to bring the child back to the clinic for follow-up on the third day after completing the regimen.

\subsubsection{Adverse Drug Reaction}

The mother brought the child back to the clinic on the third day. She gave a history of extreme weakness in the child. She said the child became noticeably weak after the second dose of the medication (artesunate-amodiaquine) which was within 48 hours of starting the treatment. The weakness worsened after the third dose. The child experienced restless sleep during episodes of weakness. Though the fever and vomiting had been resolved within 48 hours, the child could not play with her siblings, could not eat as well as usual, and could not even drink tea. The child lay down most of the time and often walked up to lean on the mother. The child was fully conscious and alert during the episode, but she had markedly reduced limb movements and cried weakly, all which scared the mother greatly. The mother said she gave no medication other than what that given to her at the clinic. Physical examination of the child did not reveal any obvious cause of the complaint, and a diagnosis of highly probable amodiaquine-associated asthenia was made. The mother was reassured and asked to give the child glucose drinks and meals as tolerated. The condition was explained to her, and she was told that the child would recover in a few days. She was also advised not to give any medications other than glucose drinks, fluids, and food as tolerated by the child. Two days later the child was brought back to the clinic markedly improved. She had regained normal activity, ate well, and was very active. Repeat hematocrit was $25 \%$, physical examination was normal, and malarial parasite test (blood smear and microscopy) was negative.

\section{Methods}

The literature review comprised an unlimited search of Medline and PubMed Central (PMC) for abstracts and full manuscripts reporting adverse drug reactions to amodiaquine and amodiaquine-containing artemisinin combination therapies (ACTs). Authors carried out the search on 10 March 2015. Search terms were <amodiaquine AND adverse drug reaction> and <amodiaquine AND asthenia>. The search was restricted to articles published in English, but not restricted to time, location, or age. References cited in retrieved manuscripts were manually searched for relevant publications. Publications were restricted to those on amodiaquine when used in the management or prophylaxis of malaria. Publications mentioning amodiaquine-associated asthenia or body weakness were the focus of the review, and results of the search were sub-categorized into incidence, clinical features, laboratory features, aetiopathogenesis, and management of the ADR. Only directly relevant and appropriate reports were selected for this review.

\section{Results}

The search terms <amodiaquine AND adverse drug reaction> yielded 44 manuscripts on Medline and 447 on PubMed Central (PMC). The search was refined to <amodiaquine AND asthenia> which yielded 2 and 37 manuscripts on Medline and PMC, respectively. Twenty manuscripts had content related to aspects of amodiaquine related asthenia or adverse reactions to the drug. From these, the existing knowledge and gaps in knowledge of the adverse drug reactions were described under the sub-headings incidence, clinical features, laboratory features, aetiopathogenesis, and management. Table 1 summarizes some of the retrieved literature.

\subsection{Epidemiology}

Amodiaquine-associated asthenia is a complaint of some users of amodiaquine and amodiaquine containing ACTs. In 2012, Brasuer et al. reported an incidence of $17 \%$ of asthenia in 1,380 subjects who received amodiaquine-artesunate combination therapies [13]. Reports from Nigeria put the frequency between $5 \%$ and $36 \%$ with a lower incidence reported in children [12, 14]. Amodiaquine-associated asthenia was reported to be more frequent in the age group 12-45 years. The condition appears to affect both sexes equally. No studies reporting the rates of amodiaquinerelated asthenia in rural versus urban settlements were found. 
Although the initial reports of serious adverse reactions to amodiaquine applied for malaria prophylaxis were in Caucasians [15, 16], the pattern of amodiaquine-associated asthenia in Caucasians is largely unreported. More studies have been done in malaria endemic countries where the use of amodiaquine as a partner drug in artemisinin-based therapies is increasing.

\subsection{Clinical Features}

The common symptom of amodiaquine-associated asthenia is a general weakness of the body, also referred to as lethargy or listlessness, which commences after the ingestion of amodiaquine or amodiaquine-containing regimens. In the case reported here, a mother noticed that her child's movements were markedly reduced and the child became noticeably weak after the second dose was administered. Asthenia has been reported to occur after the first or subsequent doses of amodiaquine [12]. The complaint may also accompany cases of prolonged use of the drug or overdosing [10]. However, the precise relationship between dose of amodiaquine and the incidence and severity of asthenia remains to be evaluated. The duration of amodiaquine-associated asthenia ranges from days (commonly up to 72 hours after ingestion of amodiaquine) to weeks in rare instances $[14,17]$. The association of clinical features like vomiting, diarrhea, body pains, neurological and other systemic symptoms with the natural history of amodiaquine-associated asthenia are also unreported. There are no studies reporting the incidence of adverse reactions in patients with a prior history of amodiaquine-associated asthenia or other co-morbidities or organ impairments.

\subsection{Laboratory Features}

The contributions of laboratory indicators to the risk of developing amodiaquine-associated asthenia or its natural course are largely unexplored. Changes in hematologic, renal, and liver enzyme indices have been largely nonsignificant in clinical studies reporting incidences of amodiaquine-associated asthenia [18]. The evidence of biochemical changes related to aetiopathogenesis and the progress of amodiaquine-associated asthenia is inconclusive.

\subsection{Aetiopathogenesis}

A few reports have tried to explain the possible aetiopathogenesis of amodiaquine adverse effects, especially serious ones. Hepatotoxicity and agranulocytosis have been attributed to direct dose-related toxicity or hypersensitivity to amodiaquine $[19,20]$. However, adverse reactions of amodiaquine like neurologic dysfunction, gastrointestinal complaints, headache, and asthenia, are yet to be explained biologically. Akindele and Odejide in 1976 reported a case of amodiaquine-associated involuntary movements which they considered an idiosyncratic reaction [21]. In 2008, Adjei et al. supported the claim of idiosyncrasy to neurological adverse reactions [22]. Attributing idiosyncrasy to these reactions is connected to their occurring with normal therapeutic doses of amodiaquine. There are currently no aetiopathogenic studies of amodiaquine-associated asthenia; thus, it is uncertain if the condition is a dose-related toxicity, a hypersensitivity reaction, or idiosyncratic. Most reports of asthenia as an adverse drug reaction in clinical trials of amodiaquine or amodiaquine-based combination therapies simply mention the condition with no further details $[16,23]$.

\subsection{Management}

The general approach to managing adverse drug reactions is widely reported in literature. The management of adverse drug reactions depends on the grade of the reaction. Generally, serious to moderate adverse drug reactions are managed by discontinuing the medication and offering supportive interventions. Adverse drug reactions graded as mild are observed without discontinuation of therapy. The majority of reports of amodiaquine-associated asthenia from clinical trials did not indicate discontinuation or modification of therapy; the asthenia was managed by observation, and resolution occurred within days of the complaints. A report from Nigeria stated that some cases of weakness were severe and necessitated prolonged hospital admission, stoppage of therapy, and intravenous infusion of dextrose fluids [24]. However, the literature search identified no other reports of amodiaquine-associated asthenia managed as a serious adverse reaction. The patient in the case reported in the current paper had already completed the dose of artesunateamodiaquine and had recovered within three days of the adverse reaction without any specific intervention. There is an overwhelming amount of evidence of the high efficacy of artesunate-amodiaquine and ACTs generally in the management of malaria, and the side effects including asthenia did not limited the administration and efficacies of the regimens $[8,10,18,23,25-30]$.

\section{Discussion}

Asthenia attributable to amodiaquine is an adverse effect of the drug; however, proving causality between the drug and the adverse reaction is challenging as with the majority of adverse drug reactions [31]. It is difficult to be certain about the association between drug exposure and possible toxicity or adverse reaction in the majority of cases [32]. It is important to remember that medicines contain not only the desired active component, but also numerous other chemicals which are added to make the drug more palatable, more soluble, more stable, or for a variety of other reasons (e.g., to add coloring, to enhance drug-drug suspension). Thus, every component of drug formulation is a substance with the potential of producing an adverse reaction [32]. This may contribute to reasons why adverse drug reactions continue to go unrecognized and unreported.

Health workers are often unsure about where the disease stops and a drug reaction begins, as this distinction may be difficult to make. There are still many challenges to recognizing and monitoring adverse drug reactions generally and specifically. There is a general lack of understanding of adverse drug reactions among health workers [33]. Asthenia (body weakness) may be a presenting symptom of malaria or other acute illnesses; it is a common symptom of many illnesses. In addition, weakness occurs with antimalarial medications, including artemether-lumefantrine, chloroquine, and mefloquine [25, 26]. These may explain why asthenia as an adverse drug effect has not been extensively studied.

Amodiaquine is extensively metabolized in the liver, and the metabolites are excreted in the urine. Severe reactions to amodiaquine include hepatotoxicity and agranulocytosis which have been attributed to direct toxic effects on the liver that are either dose-dependent or idiosyncratic reactions, or both [15, 20, 34-39]. 
Table 1. Summary of literature review on amodiaquine-related asthenia

\begin{tabular}{|c|c|c|}
\hline Amodiaquine Asthenia & First Author, Year of Publication & Summary of Asthenia-Related Aspects \\
\hline \multirow{4}{*}{ Incidence } & Bassi PU, 2013 & $\begin{array}{l}\text { A Cohort Event Monitoring (CEM) study of safety of artemisinin-based combination } \\
\text { therapies, ACTs (amodiaquine-artesunate, AS+AQ and artemether-lumefantrine, AM- } \\
\text { L). General body weakness was the most common adverse event in both groups. } \\
\text { Frequency was } 36.6 \% \text { in those treated with amodiaquine-artesunate. }\end{array}$ \\
\hline & Brasseur P, 2012 & $\begin{array}{l}\text { A nine-year CEM-based study of the safety of artesunate-amodiaquine (ASAQ) at five } \\
\text { peripheral health facilities in a rural district of southwestern Senegal. Twelve percent } \\
(12 \%) \text { had at least one adverse event. Weakness (asthenia) constituted } 17 \% \text { of adverse } \\
\text { events. }\end{array}$ \\
\hline & Adjei GO, 2008 & $\begin{array}{l}\text { A randomized clinical trial with a one-year follow-up. Complaints of fatigue and } \\
\text { excessive sleepiness were reported by five }(4.3 \%) \text { and four }(3.6 \%) \text { subjects in the } \\
\text { AS+AQ and AM-L groups, respectively. }\end{array}$ \\
\hline & Zwang J, 2012 & $\begin{array}{l}\text { An individual patient tolerability analysis from eight randomized controlled clinical } \\
\text { trials conducted at } 17 \text { sites in nine sub-Saharan countries comparing ASAQ to other anti- } \\
\text { malarial treatments. }\end{array}$ \\
\hline \multirow{3}{*}{ Clinical features } & Bassi PU, 2013 & $\begin{array}{l}\text { Most adverse events, including body weakness, occurred from day } 1 \text { and peaked by day } \\
2 \text { and } 3 \text { of medication with the mean duration of events being } 3 \text { days. A few events did } \\
\text { not follow this pattern. }\end{array}$ \\
\hline & Adisa R, 2008 & $\begin{array}{l}\text { General body weakness, headache, dizziness, and palpitations were the most common } \\
\text { adverse reactions associated with the use of amodiaquine. }\end{array}$ \\
\hline & Adjei GO, 2008 & $\begin{array}{l}\text { A randomized clinical trial with a one-year follow-up duration. The majority of adverse } \\
\text { events presented within the first three days of commencing therapy; however, the period } \\
\text { of onset and duration of body weakness were not stated. }\end{array}$ \\
\hline \multirow{4}{*}{ Laboratory features } & Zwang J, 2012 & $\begin{array}{l}\text { The risk of weakness after treatment with ASAQ was higher in patients with } \\
\text { parasitological failure. }\end{array}$ \\
\hline & Adjei GO, 2008 & $\begin{array}{l}\text { No significant changes in hematological parameters monitored were recorded in the } \\
\text { study. Participants who reported weakness apparently had no associated laboratory } \\
\text { features. }\end{array}$ \\
\hline & Olliaro P, 2000 & $\begin{array}{l}\text { A complete biochemical and hematological evaluation was performed during the study. } \\
\text { No associations were reported to be linked with amodiaquine-related adverse reactions. }\end{array}$ \\
\hline & Okoli CO, 2010 & $\begin{array}{l}\text { A randomized prospective, non-comparative study in children aged } 2 \text { to } 12 \text { years. No } \\
\text { association between hematological indices (hemoglobin concentration, white blood cell } \\
\text { and differential counts) and amodiaquine adverse effects was seen. }\end{array}$ \\
\hline \multirow[t]{3}{*}{ Aetiopathogenesis } & Metushi IG, 2014 & $\begin{array}{l}\text { Details the role of immune-mediated reactions in amodiaquine-induced idiosyncratic } \\
\text { liver injury in a mouse model. }\end{array}$ \\
\hline & Adjei GO, 2009 & $\begin{array}{l}\text { A report of two cases of rare adverse reactions to amodiaquine. One of the cases had } \\
\text { involuntary movements and weakness with a profile suggesting an idiosyncratic reaction } \\
\text { to amodiaquine. }\end{array}$ \\
\hline & Zwang 2012 & $\begin{array}{l}\text { Adverse events were significantly more related to the pre-treatment prevalence of the } \\
\text { symptom. The risk of body weakness was higher in those with malaria treatment failure. }\end{array}$ \\
\hline \multirow{5}{*}{ Management } & Olliaro P, 2000 & $\begin{array}{l}\text { Reported adverse reactions to amodiaquine were mild to moderate with no reports of } \\
\text { worsening during or after therapy. No specific interventions for mild to moderate } \\
\text { adverse reactions to amodiaquine were given. }\end{array}$ \\
\hline & Maiteki-Sebuguzi C, 2008 & $\begin{array}{l}\text { A longitudinal, single blind, randomized clinical trial in children. Amodiaquine-related } \\
\text { weakness was among the self-limiting mild-moderate adverse events recorded and did } \\
\text { not result in treatment interruption. }\end{array}$ \\
\hline & Okoli CO, 2010 & $\begin{array}{l}\text { Weakness was noticed on or after day four of therapy and resolved slowly, with only } \\
18 \% \text { resolving completely at the conclusion of the follow-up period (day 14). Side } \\
\text { effects did not warrant discontinuation of treatment. Three participants who developed } \\
\text { severe weakness were admitted and placed on dextrose infusion. No other specific } \\
\text { intervention was instituted to ameliorate weakness. }\end{array}$ \\
\hline & Egunsola O, 2013 & $\begin{array}{l}\text { A systematic review of artemisinin-based therapies (ACTs). Weakness was among the } \\
\text { mild, self-limiting, adverse effects reported. }\end{array}$ \\
\hline & Zwang J, 2012 & $\begin{array}{l}\text { Weakness as an adverse drug event was more likely in those with weakness as a } \\
\text { symptom at presentation. Weakness was mild-moderate and self-limiting. }\end{array}$ \\
\hline
\end{tabular}

The precise mechanisms involved in idiosyncratic reactions (type B reactions) are poorly understood [40]. There is little information on the possible mechanisms that may underlie other milder amodiaquine-associated adverse effects, including asthenia, despite the relatively long history of use of this drug [9]. Despite the scaling up of amodiaquine use in malaria endemic countries, studies aimed at mechanistic evaluation of adverse drug reactions to amodiaquine are few. Most of the information on reactions comes from clinical trials evaluating the efficacies of amodiaquine combination therapies with a listing of weakness and other mild-moderate symptoms / signs / laboratory findings observed during trials under the adverse events segment.

The literature is scarce on many aspects of amodiaquineassociated asthenia. Questions that remain unresolved include those related to the detailed evaluation of adverse drug reactions. These questions include: To what degree is amodiaquine-associated asthenia responsible for poor adherence to therapy? Is asthenia a reason for choosing other 
regimens not containing amodiaquine in some populations? What are the risk factors for developing adverse reactions for an individual exposed to amodiaquine? Can methods for better detecting and monitoring reactions in children be developed? Is the reaction a predisposing factor for the serious adverse reactions to amodiaquine? Whether amodiaquine-associated asthenia is dose-dependent or idiosyncratic is largely unknown. Approaches to recognizing and monitoring adverse drug reactions in children who cannot communicate effectively need to be developed.

An obvious limitation of this review is that only manuscripts written in English were used. Although Medline and PMC are popular databases of health information, not searching other databases is another limitation of this study. Nevertheless, it is hoped that this paper will stimulate further work that will refine, build on, and expand what is presented here.

\section{Conclusion}

In conclusion, amodiaquine-associated asthenia has been reported to occur in up to $36 \%$ of users of the medication, including when used in combination therapies. The condition can be frightening to patients and caregivers as illustrated in the case reported here. Despite this, the literature search revealed a scarcity of studies evaluating the epidemiology, risk factors, clinical features, and possible aetiopathogenesis of the condition. This adverse reaction may be why some clients avoid using amodiaquine containing artemisinin combination therapies. There is a need for well-structured research on this adverse effect of amodiaquine. There is still much to be investigated, and the scaling up of amodiaquinecontaining-artemisinin -based therapies demands that safety profiles be more detailed than what is currently being reported in the majority of clinical trials.

\section{Acknowledgements}

The authors express their sincere appreciation to Mrs. Abdulsalam, Ms. Grace Egunyomi, Mrs. Bolatito Akinyele, Drs. Yusuf, Azees, Borokini, and Olusola and the village health workers; they handled various aspects of patient care during the project. The authors also wish to thank the child and her parents for their cooperation and for agreeing to the publication of the case. The authors are grateful to the authorities of the National Library of Medicine for the invaluable PubMed and PMC databases, which were accessed in this study.

\section{Authors' Contributions}

OSM conceived the concept of this paper; all authors contributed significantly to the project and manuscript.

\section{Financial Disclosure}

The authors declare no financial advantages that require disclosure.

\section{Funding/Support}

None received.

\section{References}

1. Margraff F, Bertram D. Adverse drug reaction reporting by patients: an overview of fifty countries. Drug Saf. 2015;37(6):409-19. doi: 10.1007/s40264-014-0162-y

2. Carleton B, Poole R, Smith M, Leeder J, Ghannadan R, Ross C, et al. Adverse drug reaction active surveillance: developing a national network in Canada's children's hospitals. Pharmacoepidemiol Drug
Saf. 2009;18(8):713-21. doi: 10.1002/pds.1772

3. Carleton BC, Smith MA, Gelin MN, Heathcote SC. Paediatric adverse drug reaction reporting: understanding and future directions. Can J Clin Pharmacol. 2007;14(1):e45-57.

4. Munoz MJ, Ayani I, Rodriguez-Sasiain JM, Gutierrez G, Aguirre C. [Adverse drug reaction surveillance in pediatric and adult patients in an emergency room]. Med Clin (Barc). 1998;111(3):92-8.

5. Oshikoya KA, Awobusuyi JO. Perceptions of doctors to adverse drug reaction reporting in a teaching hospital in Lagos, Nigeria. BMC Clin Pharmacol. 2009;9:14. doi: 10.1186/1472-6904-9-14

6. Mokuolu OA, Okoro EO, Ayetoro SO, Adewara AA. Effect of artemisinin-based treatment policy on consumption pattern of antimalarials. Am J Trop Med Hyg. 2007;76(1):7-11.

7. FMOH. Federal Ministry of Health, Nigeria National Antimalarial Treatment Policy [PDF]. Abuja, Nigeria: National Malaria and Vector Control Division; 2005 [2016 May 31]. Available from: http://apps.who.int/medicinedocs/documents/s18401en/s18401en.pd f.

8. Graupner J, Gobels K, Grobusch MP, Lund A, Richter J, Haussinger D. Efficacy of amodiaquine in uncomplicated falciparum malaria in Nigeria in an area with high-level resistance to chloroquine and sulphadoxine/pyrimethamine. Parasitol Res. 2005;96(3):162-5. doi: 10.1007/s00436-005-1325-7

9. Woodtli W, Vonmoos P, Siegrist P, Zollikofer H. [Amodiaquineinduced hepatitis with leukopenia]. Schweiz Med Wochenschr. 1986;116(29):966-8.

10. Olliaro P, Mussano P. Amodiaquine for treating malaria. Cochrane Database Syst Rev. 2003;2000(2):CD000016.

11. Sinclair D, Zani B, Donegan S, Olliaro P, Garner P. Artemisininbased combination therapy for treating uncomplicated malaria. Cochrane Database Syst Rev. 2009(3):CD007483. doi: 10.1002/14651858.cd007483.pub2

12. Bassi PU, Osakwe AI, Isah A, Suku C, Kalat M, Jalo I, et al. Safety of artemisinin-based combination therapies in Nigeria: a cohort event monitoring study. Drug Saf. 2013;36(9):747-56. doi: 10.1007/s40264-013-0044-8

13. Brasseur P, Vaillant MT, Olliaro PL. Anti-malarial drug safety information obtained through routine monitoring in a rural district of South-Western Senegal. Malar J. 2012;11:402. doi: 10.1186/14752875-11-402

14. Adisa R, Fakeye TO, Dike D. Evaluation of adverse drug reactions to artemisinin-based combination therapy in a Nigerian University Community. Trop J Pharm Res. 2008;7(2):937-44. doi: 10.4314/tjpr.v7i2.14680

15. Neftel KA, Woodtly W, Schmid M, Frick PG, Fehr J. Amodiaquine induced agranulocytosis and liver damage. Br Med J (Clin Res Ed). 1986;292(6522):721-3. doi: 10.1136/bmj.292.6522.721

16. Wittes R. Adverse reactions to chloroquine and amodiaquine as used for malaria prophylaxis: a review of the literature. Can Fam Physician. 1987;33:2644-9.

17. Adjei GO, Kurtzhals JA, Rodrigues OP, Alifrangis M, Hoegberg LC, Kitcher ED, et al. Amodiaquine-artesunate vs artemetherlumefantrine for uncomplicated malaria in Ghanaian children: a randomized efficacy and safety trial with one year follow-up. Malar J. 2008;7:127. doi: 10.1186/1475-2875-7-127

18. Zwang J, Dorsey G, Djimde A, Karema C, Martensson A, Ndiaye JL, et al. Clinical tolerability of artesunate-amodiaquine versus comparator treatments for uncomplicated falciparum malaria: an individual-patient analysis of eight randomized controlled trials in Sub-Saharan Africa. Malar J. 2012;11:260. doi: 10.1186/1475-2875$11-260$

19. Metushi IG, Cai P, Dervovic D, Liu F, Lobach A, Nakagawa T, et al. Development of a novel mouse model of amodiaquine-induced liver injury with a delayed onset. J Immunotoxicol. 2015:12(3):247-60. doi: 10.3109/1547691X.2014.934977

20. Lind DE, Levi JA, Vincent PC. Amodiaquine-induced agranulocytosis: toxic effect of amodiaquine in bone marrow cultures in vitro. $\mathrm{Br}$ Med J. 1973;1(5851):458-60. doi: 10.1136/bmj.1.5851.458

21. Akindele MO, Odejide AO. Amodiaquine-induced involuntary movements. BMJ. 1976;2(6029):214-5. doi:10.1136/bmj.2.6029.214

22. Adjei GO, Goka BQ, Rodrigues OP, Hoegberg LC, Alifrangis M, Kurtzhals J. Amodiaquine-associated adverse effects after inadvertent overdose and after a standard therapeutic dose. Ghana Med J. 2009;43(3):135-8.

23. McIntosh HM, Olliaro P. Artemisinin derivatives for treating uncomplicated malaria. Cochrane Database Syst Rev. 2000(2):CD000256.

24. Okoli CO, Ugwu CE, Ubaka MC, Ezike CA, Akah AP. Efficacy of artesunate-amodiaquine combination therapy for uncomplicated 
malaria in patients in south-eastern Nigeria. J Appl Res. 2010;10(1):17-23.

25. Maiteki-Sebuguzi C, Jagannathan P, Yau VM, Clark TD, NjamaMeya D, Nzarubara B, et al. Safety and tolerability of combination antimalarial therapies for uncomplicated falciparum malaria in Ugandan children. Malar J. 2008;7:106. doi: 10.1186/1475-2875-7106

26. Falade C, Manyando C. Safety profile of Coartem: the evidence base. Malar J. 2009;8 Suppl 1:S6. doi: 10.1186/1475-2875-8-S1-S6

27. Falade CO, Ogundele AO, Yusuf BO, Ademowo OG, Ladipo SM. High efficacy of two artemisinin-based combinations (artemether-lumefantrine and artesunate plus amodiaquine) for acute uncomplicated malaria in Ibadan, Nigeria. Trop Med Int Health. 2008;13(5):635-43. doi: 10.1111/j.13653156.2008.02043.x

28. Egunsola O, Oshikoya KA. Comparative safety of artemetherlumefantrine and other artemisinin-based combinations in children: a systematic review. Malar J. 2013;12:385. doi: 10.1186/1475-287512-385

29. Osorio L, Gonzalez I, Olliaro P, Taylor WR. Artemisinin-based combination therapy for uncomplicated Plasmodium falciparum malaria in Colombia. Malar J. 2007;6:25. doi: 10.1186/1475-2875-625

30. White NJ. Delaying antimalarial drug resistance with combination chemotherapy. Parassitologia. 1999;41(1-3):301-8.

31. Naranjo CA, Busto U, Sellers EM, Sandor P, Ruiz I, Roberts EA, et al. A method for estimating the probability of adverse drug reactions. Clin Pharmacol Ther. 1981;30(2):239-45. doi:10.1038/clpt.1981.154

32. Choonara I, Rieder MJ. Drug Toxicity and adverse drug reactions in children, a brief historical review. Paediatr Perinat Drug Ther. 2002;5(1):12-6.

33. Oshikoya KA. Adverse drug reactions in children: types, incidence, and risk factors. Niger J Paediatr. 2006;33(2):29-35.

34. Lepeu G, Codine P, Janbon F, Bertrand A. [Amodiaquineinduced agranulocytosis]. Nouv Presse Med. 1981;10(34):2827-8.

35. Douer D, Schwartz E, Shaked N, Ramot B. Amodiaquine-induced agranulocytosis: drug inhibition of myeloid colonies in the presence of patient's serum. Isr J Med Sci. 1985;21(4):331-4.

36. Rhodes EG, Ball J, Franklin IM. Amodiaquine induced agranulocytosis: inhibition of colony growth in bone marrow by antimalarial agents. Br Med J (Clin Res Ed). 1986;292(6522):717-8. doi: 10.1136/bmj.292.6522.717

37. Aymard JP, Rouveix B, Ferry R, Janot C, May T, Legras B, et al Amodiaquine-induced agranulocytosis: report of a case with in vitro studies of granulocyte-macrophage progenitor cells. Acta Haematol. 1989;82(1):40-2. doi: 10.1159/000205276

38. Clarke JB, Neftel K, Kitteringham NR, Park BK. Detection of antidrug $\mathrm{IgG}$ antibodies in patients with adverse drug reactions to amodiaquine. Int Arch Allergy Appl Immunol. 1991;95(4):369-75. doi: 10.1159/000235475

39. Uetrecht J. Role of animal models in the study of drug-induced hypersensitivity reactions. Aaps J. 2005;7(4):E914-21. doi: 10.1208/aapsj070489

40. Park BK, Pirmohamed M, Kitteringham NR. Idiosyncratic drug reactions: a mechanistic evaluation of risk factors. $\mathrm{Br} \mathrm{J}$ Clin Pharmacol. 1992;34(5):377-95. doi: 10.1111/j.13652125.1992.tb05647.x 